\title{
INVESTIGACIÓN DE ECOLOXÍA ESCOLAR NUNHA PRADARÍA DE ZOSTERA NOLTEII
}

\section{SCHOLAR ECOLOGICAL RESEARCH ON A ZOSTERA NOLTEII MEADOW}

http://dx.doi.org/10.15304/ie.29.6342

Francisco Sóñora Luna

Director do Proxecto Climántica Departamento de Ciencias Naturais IES Virxe do Mar Área de Didáctica das Ciencias Experimentais Universidade de Santiago de Compostela (USC) francisco.sonora@usc.es

Emilio Fernández Suárez Facultade de Ciencias do Mar Universidade de Vigo esuarez@uvigo.es

Carlota Barañano Carrión Facultade de Ciencias do Mar Universidade de Vigo carlota.bcarrion@hotmail.com

Aitor Alonso Méndez

Webmaster do Proxecto Climántica Universidade de Santiago de Compostela (USC) aitor@educo2cean.org

\section{RESUMO}

Analízase a situación da pradaría de Zostera nolteii do banco de marisqueo de bivalvos de Testal (Noia), mediante a investigación desenvolvida por escolares, coa dirección de científicos. A finalidade do programa de Ciencia Escolar de Climántica é contribuír ao coñecemento científico mediante a obtención de series de datos útiles para a realización de investigacións de interese a escala local. 
Neste caso, analizouse a relación existente entre as abundancias de bivalvos de interese comercial e a presenza da fanerógama Zostera nolteii co obxectivo de capacitar ao alumnado para facer ciencia sobre os impactos humanos sobre os servizos ecosistémicos máis relevantes da súa contorna. Con esta colaboración entre Ciencia e Escola, conseguiuse aumentar a competencia científica do alumnado, ao tempo que se realizaron transferencias bidireccionais ciencia - escola no eido da investigación e educación sobre o cambio global.

A actividade que se describe neste traballo ten como obxectivo xeral coñecer a relación existente entre a diversidade de organismos animais do banco do Testal e a presenza e distribución espacial da fanerógama Zostera nolteii, para así entender o seu papel como xeradora de estrutura no ecosistema intermareal de substrato brando.

Palabras clave: Ecoloxía escolar, pradarías mariñas, impactos humanos, cambio global, marisqueo.

\section{ABSTRACT}

The present article addresses the study of the state of a Zostera nolteii meadow at the Testal shellfish bank (Noia, Spain). Scholars supported by scientists carried out the study. The aim of the Climantica scholar science program is to contribute to the scientific knowledge through the development of local data series of ecological interest. In this case, the relationship between the abundance of bivalves and the presence of Zostera nolteii was assessed. The main aim of this activity was to train students to scientifically explore and evaluate human impacts on the most relevant ecosystem services in their area. This collaboration between science and school, allowed students to increase their scientific skills and, at the same time, they developed bidirectional transference between science and school.

The described activity focused on the relationship between the animal diversity at the Testal shellfish bank and the presence and distribution of Zostera nolteii, in order to understand its role in the intertidal ecosystem.

Keywords: Scholar ecology, seagrass meadows, human impacts, global change, shellfishing

\section{INTRODUCIÓN}

Esta actividade, que se levou a cabo o 22 de marzo de 2019, resultou dunha colaboración do IES Virxe do Mar con investigadores da Área de Ecoloxía da Universidade de Vigo. Desenvolveuse en paralelo coa mostraxe de bivalvos seguindo a metodoloxía da investigación escolar iniciada no ano 2017 no marco da Ciencia Escolar de Climántica (Sóñora e Alonso-Méndez, 2018).
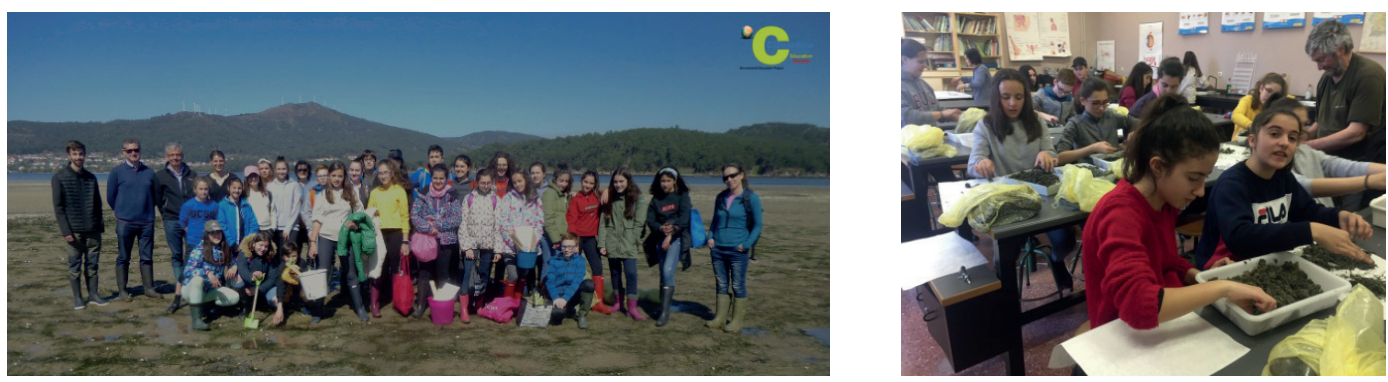

Figura 1. Imaxe do grupo de escolares cos investigadores e docentes que os orientaron na actividade (esquerda) e dos estudantes realizando a tratamento das mostras no laboratorio (dereita). 
Os antecedentes desta actividade centráronse na análise da abundancia e distribución dos bivalvos de interese comercial presentes no banco (Cerastoderma edule, Ruditapes decussatus e Ruditapes philippinarum) por clases de tamaño, atendendo a súa localización no mesolitoral medio ou no mesolitoral inferior. A partir do ano 2019, esta investigación escolar incorporou o estudo de Zostera nolteii e a súa relación cos bivalvos comerciais alí presentes. A iniciativa aspira a mellorar a competencia científica do alumnado, en especial no relativo a saber facer Ecoloxía e, ao mesmo tempo, a contribuír ao coñecemento científico sobre as posibles incidencias do cambio global na xestión do recurso.

A actividade persegue tres obxectivos compartidos pola Ciencia Escolar e a Ecoloxía:

1) Coñecer a diversidade de organismos da macrofauna que habitan enterrados no sistema intermareal de substrato brando, aplicando destrezas no procesado de mostras fangosas no laboratorio

2) Determinar se existe unha relación entre a diversidade de organismos da macrofauna no substrato brando e a presenza de Zostera nolteii

3) Comprobar se existe unha relación entre o tamaño das manchas da pradaría de Zostera nolteii e a diversidade de organismos animais

\section{MARCO CIENTÍFICO}

As pradarías de fanerógamas mariñas están constituídas por plantas con flores que, procedentes do sistema terrestre, colonizaron os hábitats intermareais ou submareais de substrato brando das zonas costeiras hai uns 70 millóns de anos. Daquela, estas especies atoparon un hábitat practicamente baleiro doutros vexetais, polo que carecían de competidores, e no que a abundancia de insectos, e por tanto a probabilidade de infeccións, eran moi reducidas.

A transición dunha especie vexetal dende o medio terrestre cara ao mariño leva aparellada unha serie de modificacións estruturais e funcionais derivadas do proceso adaptativo a un novo ambiente con características físicas e químicas ben diferentes das presentes no medio orixinal. Recentemente, Olsen et al. (2016) publicaron a secuencia completa do xenoma da especie de fanerógama mariña máis amplamente distribuída xeograficamente, Zostera marina, e comparárona coa correspondente a outra especie próxima, pero neste caso propia de augas continentais, Spirodela polyrhiza, co obxectivo de identificar que xenes perderon e cales adquiriron ao longo desde proceso adaptativo. As fanerógamas mariñas actuais carecen de estomas, as estruturas que facilitan o intercambio de gases, especialmente dióxido de carbono, coa atmosfera, proceso esencial para o crecemento das plantas terrestres. Perderon tamén os xenes envoltos na xeración de produtos volátiles ou aqueles relacionados con funcións sensoriais, como o terpeno ou o etileno, que se relacionan con procesos de comunicación a través do medio aéreo. Os xenes relacionados cos mecanismos de defensa da planta atópanse moi reducidos, como é de esperar nun ambiente con baixa taxa de infeccións, e desapareceron aqueles implicados na defensa fronte á radiación ultravioleta de tipo $\mathrm{B}$, a máis enerxética e daniña, pero con menor incidencia no océano debido a que é absorbida de xeito eficiente nos primeiros metros dos océanos. Pola contra, estas especies adquiriron xenes relacionados coa 
supervivencia nun medio de elevada salinidade e transformaron a súa parede celular, que é parecida á das algas, de xeito que o intercambio de gases como o osíxeno ou o dióxido de carbono, así como a absorción de nutrientes, se viron favorecidos.

Estas plantas colonizaron con éxito o medio mariño, como demostra a súa distribución xeográfica, estendida ao longo de todos os océanos do planeta, coa excepción do Océano Antártico (Green e Short, 2003). Constitúen un grupo reducido de especies, aproximadamente 60 no conxunto do planeta, entre as que cabe salientar dúas especies do xénero Zostera, Zostera marina e Zostera nolteii, ambas presentes nas Rías e esteiros de Galicia (Ruiz et al., 2015; García-Redondo, Bárbara e Díaz-Tapia, 2019). Son plantas perennes, con forma de herba, que presentan follas que se colocan de xeito alterno ao longo do eixo principal da planta. A reprodución pode ser sexual ou asexual. Presentan flores femininas e masculinas que se alternan nunha espiga rodeada por unha vaina, chamada espata. A fecundación é hidrófila subacuática, é dicir, acontece mediada pola auga, sendo o pole arrastrado polas correntes, polo que o éxito da reprodución sexual depende da proximidade entre as plantas. Producen froitos con sementes de tamaño facilmente observable $(2-2.5 \mathrm{~mm})$. A reprodución asexual realízase por estolóns, que permiten a expansión da planta a través de rizomas. Estes rizomas xeran un sistema de raíces moi desenvolvido que lles permite captar nutrientes e co que se fixa ao substrato, permitíndolles soportar o efecto das ondadas, mesmo das máis intensas.

As pradarías de fanerógamas mariñas exercen funcións ecolóxicas moi relevantes nos ecosistemas que ocupan. Configuran un dos ecosistemas máis produtivos do planeta, apenas superados polos cultivos terrestres (Duarte e Chiscano, 1999). Sitúanse entre os ecosistemas con maior capacidade para secuestrar carbono, representando o $20 \%$ da totalidade de carbono orgánico almacenado nos sedimentos mariños (Fourqurean et al, 2012), participando así de xeito significativo na mitigación do incremento de gases de efecto invernadoiro na atmosfera. Estas plantas teñen a capacidade de modificar a velocidade das correntes de auga ao seu paso polas pradarías (Follett, Hays e Nepf, 2019), previndo da erosión costeira, e desempeñan unha función de depuración ao actuar como filtro de nutrientes e outros compostos ben a través da absorción pola planta ou asociado a súa capacidade de reter partículas en suspensión (ex. Fernandes, Bryars, Mount e Miller, 2008).

A fragmentación e perda de cobertura destas especies vexetais está asociada non só a unha perda da biodiversidade, senón tamén á alteración das funcións propias do ecosistema. Este proceso conduce a un descenso de produtividade, á alteración da dinámica costeira, á desestabilización do substrato e á resuspensión dos sedimentos, diminuíndo deste xeito a súa capacidade como sumidoiro de carbono e reducindo os recursos pesqueiros asociados, afectando directa e indirectamente aos seres humanos (Walker, Kendrick e McComb, 2006). Ademais, investigacións recentes desenvolvidas en illas de Indonesia teñen demostrado que a presenza de pradarías mariñas reduce ata nun $50 \%$ a concentración de bacterias patóxenas que potencialmente poden infectar humanos, peixes e invertebrados mariños (Lamb et al., 2017). A estrutura aérea e subterránea característica das comunidades dominadas por fanerógamas mariñas organiza o espazo tridimensionalmente, xerando unha elevada heteroxeneidade de hábitats que ocasiona una elevada biodiversidade en comparación coas áreas adxacentes (Hemminga e Duarte, 2000). Estas pradarías recoñécense como zonas de cría dunha variada representación de especies de moluscos e peixes (Heck, Hays e Orth, 2003), algunhas delas de interese económico, como é o caso da Sepia officinalis (choco) en Galicia. 
A ampla gama de funcións que exercen as pradarías de fanerógamas mariñas tradúcense no fornecemento de numerosos servizos ecosistémicos de moi elevado valor para a economía e o benestar das sociedades humanas. Unha investigación recente publicada por Norlund, Koch, Barbier e Creed (2016) identifica estes servizos e estuda a súa variabilidade en función das diferentes especies de fanerógamas mariñas e da súa localización xeográfica. A investigación conclúe que o número de servizos fornecidos aumenta en función do tamaño das especies, identificando ao xénero Zostera como un dos máis relevantes neste contexto. Entre os principais servizos que se identifican no estudo destacan a xeración de hábitats axeitados para invertebrados, peixes e aves, tanto nas súas fases adultas como xuvenís, a capacidade de retirar nutrientes e contaminantes da auga e de capturar carbono, a estabilización dos sedimentos e a protección costeira, a produción de materia orgánica que sostén as redes tróficas estuarinas, así como o seu uso con fins educativos, recreativos ou de investigación. Estímase que o conxunto dos servizos ecosistémicos proporcionados polas fanerógamas mariñas se pode traducir en termos económicos en preto de $17000 €$ por hectárea (Constanza et al. 1997), o que os sitúa entre os ecosistemas do planeta con máis elevado valor económico (de Groot et al., 2012). Sen embargo, as praderías mariñas son, na práctica, "invisibles", xa que a atención que merecen dos medios de comunicación é entre 3 e 100 veces menor que a que reciben os mangleiros, as marismas ou os arrecifes de coral (ver figura $7 \mathrm{~b}$ en Orth et al., 2006).

O masivo incremento da poboación humana nas áreas costeiras, unido aos cambios ambientais que acontecen a escala planetaria, orixinan que a magnitude e a velocidade do cambio nas presións ambientais ás que están sometidos estes ecosistemas sexan moi superiores ás rexistradas durante as decenas de millóns de anos nas que se estende a súa historia evolutiva. As pradarías mariñas atópanse entre os ecosistemas máis severamente afectados polos cambios ambientais antropoxénicos (Orth et al., 2006). Estímase que dende 1980 a superficie ocupada por estas especies se reduciu en $110 \mathrm{~km}^{2}$ cada ano, o que representa unha diminución global, dende dita data, do 30\% (Waycott et al., 2009). Son múltiples os procesos que causan esta regresión global. A perda de hábitats costeiros como consecuencia da expansión das áreas urbanas e industriais, da construción de novas áreas portuarias comerciais ou da extensión das existentes, e da proliferación de mariñas e áreas recreativas, atópanse entre as máis relevantes (Fonseca, Kenworthy e Whitfield, 2000). Sábese que están tamén afectadas polos procesos asociados ao cambio climático, como o incremento de temperatura dos océanos ou as modificacións na intensidade e frecuencia de fenómenos extremos, así como polo deterioro da calidade do hábitat asociado á entrada de sedimentos, nutrientes ou contaminantes aos ecosistemas costeiros (ver revisión en Orth et al, 2006). A introdución de especies non nativas tamén exercen un efecto negativo sobre algunhas destas pradarías (Ruiz et al., 2000).

As perturbacións físicas asociadas tanto á acción mecánica das áncoras dos barcos sobre o fondo mariño coma as que se derivan da extracción de recursos, principalmente moluscos, exercen un impacto negativo significativo sobre as poboacións de fanerógamas mariñas (ej. Boese, 2002; Unsworth, Williams, Jones e Cullen-Unsworth, 2017). Son numerosas as áreas xeográficas do planeta nas que as pradarías mariñas coexisten con actividades de explotación de recursos mariños, tanto pesca como marisqueo (Norlund, Unsworth, Gullstrom e Cullen-Unsworth, 2017). No caso de Galicia, un traballo recente publicado por García-Redondo et al. (2019) indica que o $80 \%$ da superficie cuberta por Zostera marina está afectada polas presións ambientais asociadas á actividade marisqueira. $\mathrm{O}$ 
marisqueo causa perturbacións físicas sobre as pradarías desta especie, podendo chegar a reducir a súa biomasa de xeito moi significativo, aínda que a capacidade de recuperación durante o período de veda da extracción de moluscos pode ser moi elevada (Barañano, Fernández, Méndez e Troncoso, 2017). Tense demostrado tamén que a actividade marisqueira reduce nun $50 \%$, aproximadamente, a capacidade de capturar carbono por parte das pradarías mariñas (Barañano, Fernández e Méndez, 2018). En consecuencia, a implantación de medidas que favorezan a coexistencia da actividade marisqueira coa integridade das funcións destes ecosistemas e dos servizos que fornecen, debe ser un dos retos da xestión integrada das zonas costeiras de cara ao futuro.

As características ecolóxicas destas comunidades convértenas en candidatas moi axeitadas para a introdución do seu estudo na escola. Trátanse de ecosistemas de acceso doado para os estudantes, constituídos por organismos macroscópicos, de mostraxe sinxelo, facilmente observables e manipulables, o que facilita a experimentación en laboratorios escolares. Pero resulta aínda máis relevante o feito de que a grande variedade de funcións ecolóxicas nas que interveñen estas comunidades de fanerógamas, a ampla gama de presións ás que están sometidas e a intensidade dos impactos que experimentan, converten a estas especies en sentinelas biolóxicas axeitadas para realizar o seguimento das condicións ambientais dos ecosistemas costeiros. Non sorprende, polo tanto, que sexan definidas como "canarios costeiros" pola súa similitude cos paxaros que se introducían no interior das minas a principios do século pasado para alertar de xeito temperán sobre a existencia de gases, antes de que estes acadaran concentracións que resultaran en explosións. Polo tanto, o seu estudo na escola a medio e longo prazo, de xeito continuado en sucesivos cursos académicos, permitirá analizar a variabilidade temporal das características ambientais e, consecuentemente, dos impactos asociados aos procesos de cambio global que estean a acontecer na zona de estudo. Ao mesmo tempo, permitirá investigar, en particular, a resposta destes ecosistemas fronte a perturbacións relacionadas coas actividades humanas, coma por exemplo o marisqueo.

\section{MARCO DIDÁCTICO}

O marco didáctico encádrase na Pedagoxía Social Escolar dende un enfoque Ciencia Tecnoloxía Sociedade, tomando como referencia de teoría de aprendizaxe básica o socioconstrutivismo. Para iso recórrese aos principios de deseño do proxecto Climántica (Sóñora, 2011), que xa foron aplicados no estudo deste ecosistema (Sóñora e Alonso-Méndez, 2018). Entre os seus postulados destaca o papel que a escola de secundaria pode representar como ponte eficaz entre a ciencia, a tecnoloxía e a sociedade para facer chegar á cidadanía o reto do cambio global e, en particular, do cambio climático.

Este estudo adquire relevancia na xestión deste ecosistema que xera recursos económicos de importancia para 15000 habitantes, desde un sector primario básico tradicional. Neste sentido, a investigación de Ciencia Escolar implicada neste estudo vai máis aló do seu potencial para o desenvolvemento da competencia científica na poboación escolar, xa que tamén é relevante desde o punto de vista socio - ecolóxico - económico. Isto é así porque o alumnado colabora cos científicos e coa organización de produtores para comunicar aos mariscadores e mariscadoras mensaxes sobre posibles medidas de xestión deste ecosistema co obxectivo de acadar a sustentabilidade do recurso, diante dos impactos do cambio global. 
Buscouse unha interacción entre o alumnado, os docentes, os investigadores da Área de Ecoloxía e a bióloga da Confraría en consonancia co concepto extraído da Teoría Sociocultural (Vygotski, 1978a) de Zona de Desenvolvemento Próximo (ZDP) como recurso para xerar os contextos de interacción implicados nesta investigación da Ciencia Escolar. Profesores de secundaria, investigadores universitarios e persoal técnico da Confraría facilitaron que o alumnado alcanzara un nivel de formación máis elevado do que podería alcanzar nun currículo escolar convencional, sobre todo no relativo á competencia científica. Esta triangulación, favorecedora da potenciación da competencia científica do alumnado, ampliou o concepto ZDP ao engadirlle a compoñente de "andamiaxe" (Bruner, 1986). Para conseguilo, achegouse un suplemento importante de axudas, relativamente ás ordinarias na mediación curricular necesaria para achegar o coñecemento aos estudantes, que de forma convencional recae nos docentes. Neste caso en concreto, tamén participaron na mediación, ademais dos docentes habituais, científicos da Área de Ecoloxía da Universidade de Vigo e a bióloga da Confraría de Mariscadores.

Esa "andamiaxe" resultante da triangulación das axudas de mediación, iniciouse xa no comezo do proceso da aprendizaxe vinculado a esta experiencia, coa chegada dos investigadores universitarios ao banco marisqueiro. Nese momento produciuse o máximo nivel de axuda (provisión de impulso motivador, visións que delimitaron e simplificaron o problema ecolóxico, guía nos aspectos clave da actividade, presentación de modelos científicos compatibles cos modelos mentais e ideas previas dos alumnos ...) e continuou ao longo do proceso ata o último chanzo da súa estadía, momento no que a directividade do ensinante foise minimizando e os estudantes foron tomando o control, recollendo datos, procesándoos no laboratorio e integrándoos na aula de informática.

Seguiuse así o enfoque proposto polo Construtivismo que postula que o coñecemento non é un proceso de recepción pasiva de información, senón que en realidade é o resultado da actividade propositiva que o suxeito realiza cos obxectos do mundo (Pardo Pérez, 2015). Neste proceso activo, que arrinca da curiosidade natural do alumnado, situado no propio contexto obxecto de estudo, os estudantes motiváronse e esforzáronse en dar sentido aos problemas que se lle presentaron no propio banco marisqueiro. Para elo aplicaron o seu marco de referencia, xa sexan esquemas ou modelos mentais ou outro tipo de construtos persoais acordes co seu nivel de competencia curricular en Ecoloxía, que non era moi elevado, posto que a maioría dos estudantes implicados eran estudantes de $1^{\circ}$ e $2^{\circ}$ de ESO (13-14 anos).

As orixes da inspiración desta investigación de Ecoloxía Escolar atópase tamén no pensamento pedagóxico de William Kilpatrick (1921) e do seu mestre John Dewey (1896), materializado no Método de Proxectos. Nesa liña enténdese o protagonismo, confianza, autonomía e liberdade que se lle deu aos alumnos que participaron nesta investigación, na que actuaron de forma moi similar a como o fan os investigadores que participan en proxectos de investigación de xeito profesional. Nese sentido actuouse en coherencia coa definición que lle deu o propio Kilpatrick ao seu método como un modelo metodolóxico que ofrece oportunidades aos estudantes de enfrontar con éxito os problemas da vida.

Ao longo da investigación de Ecoloxía Escolar axudouse ao estudante a recoller datos de forma rigorosa, sistemática, relevante e significativa, para desenvolver, a partir da súa análise e 
procesado, consideracións máis elaboradas válidas para tomar decisións e desenvolver as actitudes sociais sobre as decisións adoptadas. Nesa liña xerouse no alumnado un interese por responder a interrogantes que se lle presentan in situ, para impulsar un proceso de capacitación na competencia científica que lle leve a buscar resposta coa intención de satisfacer o desexo natural de aprender. En concreto seguiuse a categoría de Proxectos de investigación definida polo propio Kilpatrick, neste caso sobre a relevancia que ten Zostera nolteii para o funcionamento do ecosistema intermareal e para a mellora da súa xestión nun contexto de cambio ambiental de escala global.

A versión do Método de Proxectos que se seguiu é a actualización desenvolta no proxecto Climántica (Sóñora, 2007). Esta actualización transfire a Ciencia á Sociedade a través de proxectos escolares que impliquen a colaboración de investigadores en Ciencia cos docentes dos centros escolares, ampliando así o principio establecido por Kilpatrick de que o proxecto debe permitir a inclusión das familias e a comunidade educativa. Iso situou ao profesorado como un nexo de unión e mediación entre o alumnado, a asociación de produtores e a investigación ecolóxica.

Estamos, pois, diante unha aprendizaxe baseada no compartir, descubrir, construír e reconstruír o coñecemento de maneira colaborativa tutelada polos científicos. Deste xeito foméntase a autonomía e desenvolvemento íntegro do alumnado, a relación e respecto entre iguais xunto coa inclusión e colaboración entre a ciencia en particular e a sociedade en xeral. Por tanto o Método de Proxectos utilizado neste estudo vai máis aló que o orixinal no que se inspira establecido por Kilpatrick seguindo a liña do "aprender facendo" do seu mestre Dewey, porque o alumnado non só aprende facendo, senón que tamén xera coñecemento avanzando na construción de series inéditas e de elevado potencial para a análise e xestión do ecosistema.

Este enfoque de actualización do Método de Proxectos está orientado tamén pola aprendizaxe por descubrimento, incorporando as variantes xurdidas das críticas de Ausubel (2000), para non quedar no simple activismo e conseguir que o alumnado aprenda conceptos e principios ecolóxicos que garantan un coñecemento tan rigoroso como o que permita o seu nivel de competencia curricular. Ao mesmo tempo se procurou que os alumnos aprendesen a falar de Ecoloxía no encadre da ZDP de Vygotski. Por iso fomentouse a argumentación oral, buscando que o alumnado, a medida que se ía avanzando no proceso, se fora abstraendo das observacións concretas reflectidas nos datos que rexistraban, para pensar sobre conceptos ecolóxicos, estimulando o pensamento hipotéticodedutivo. Nese sentido percorreuse ao principio metodolóxico expresado por Ausubel (2000) de que desde a transmisión tamén é posible propiciar a actividade de aprendizaxe creadora de comprensión significativa do mundo.

Coa intención de lograr unha transmisión eficaz dos conceptos de Ecoloxía, partiuse do que xa sabían os estudantes, para organizar de forma lóxica e psicolóxica a secuencia de contidos demandando do alumnado a súa participación mediante a interacción verbal no campo, no laboratorio e na aula de informática. Ao longo dese proceso buscouse que ao falar de e sobre Ecoloxía, os estudantes construíran pontes entre o que sabían e o que estaban a analizar (Álvarez e Del Río, 1990) para conseguir que foran capaces de xerar modelos mentais que faciliten a comprensión básica das relacións ecolóxicas analizadas. Neste sentido tívose en conta a visión pedagóxica de Bruner (1985), quen sostén que a aprendizaxe por descubrimento debe estar conducida por procesos de 
ensino e aprendizaxe que sexan facilitadores da apropiación do coñecemento polo estudante nunha comunidade formada por persoas que comparten un mesmo sentido das cousas, neste caso o interese pola formación ecolóxica para comprender, xerar e expresar coñecementos que dean respostas acertadas á xestión do banco de marisqueo de Testal ao cambio global. Por iso nesta investigación púxose en valor a transacción lingüística que se deriva das perspectivas construtivistas socio-culturais, e que comporta para a educación escolar unha gramática didáctica da que forman parte conceptos e enfoques prácticos derivados como, "ZDP”, "andamiaxe", "axuda axustada", "participación guiada", "ensino e aprendizaxe dialóxica", "grupos interactivos", "aprendizaxe colaborativa e cooperativa", “comunidades de aprendizaxe”, "comunidades de práctica”, etc. (Pardo Pérez, 2015).

No encadre didáctico desta actividade concreta de Ecoloxía tomou especial relevancia o concepto constructuvista de "contexto" desde o enfoque da "complexidade dos problemas" como estímulo para a aprendizaxe significativa. Para iso recorreuse a estimular "o pensamento complexo" (Morin, 1990), para afrontar o coñecemento dun xeito multidimensional. Seguiuse así ao devandito autor no seu postulado de que este concepto de "complexidade" aspira a que o alumnado adquira comprensións multidimensionais do mundo fronte ao pensamento simplificador e reducionista (Pardo Pérez, 2015). Procurouse por tanto afastar a abordaxe conceptual do saber ecolóxico requirido pola experiencia, do pensamento reducionista moitas veces usado no noso sistema educativo no que predominan os procesos de ensino e aprendizaxe mediados por libros de texto. $\mathrm{O}$ uso do pensamento complexo acoplado a procesos de aprender facendo e falando de Ecoloxía, permite interiorizar a transferencia da Ecoloxía ao ámbito escolar ao que aspira esta experiencia curricular. Isto resulta tamén coherente coa teoría da aprendizaxe significativa de Ausubel que postula que unha aprendizaxe é tanto máis significativa cantas máis relacións establece o novo contido con conceptos e conectores relevantes da estrutura cognitiva do suxeito.

\section{METODOLOXÍA}

O presente traballo susténtase no desenvolvemento dunha actividade de campo e laboratorio na pradaría intermareal de Zostera nolteii situada no banco marisqueiro de Testal (Noia, A Coruña) e que estivo orientada por catro obxectivos propios da Ecoloxía Escolar:

1. Aprender a metodoloxía de mostraxe de flora e fauna en ecosistemas intermareais dominados por fanerógamas mariñas.

2. Cuantificar a abundancia e biomasa de Zostera nolteii en manchas poboacionais de diferente tamaño.

3. Avaliar o efecto da presenza da especie Zostera nolteii sobre a diversidade fáunica e comprobar a relación existente entre esta diversidade e o tamaño das manchas de poboación da fanerógama.

4. Estudar a relación entre a presenza de Zostera nolteii e a de moluscos bivalvos.

No desenvolvemento da actividade participaron o alumnado da materia de Climántica e Club de Ciencias deste proxecto no IES Virxe do Mar. Os estudantes foron tutelados cientificamente por parte de investigadores e investigadoras da área de Ecoloxía da Universidade de Vigo. 
A metodoloxía baseada na transferencia da ciencia á escola adoptou estas catro fases:

1. Explicación no campo da actividade.

2. Mostraxe de flora e fauna no sistema intermareal.

3. Procesado das mostras no laboratorio e cuantificación da abundancia de Zostera e organismos animais.

4. Tratamento dos datos.

O interese didáctico de incorporar a complexidade inherente ao estudo das conexións entre os diferentes niveis tróficos xustifica a decisión de introducir a investigación escolar sobre Zostera á investigación sobre a abundancia de bivalvos e a súa variabilidade natural iniciada no ano 2017 na liña de Ciencia Escolar de Climántica (Sóñora e Alonso-Méndez, 2018).

O encadre metodolóxico tivo presente a necesidade de comprender as repercusións do cambio global mediante a resolución de problemas complexos abertos. Tratouse de que o alumnado entendera que a comprensión dos impactos potenciais do cambio global sobre os recursos marisqueiros do banco de Testal, require a integración do coñecemento relativo aos diferentes impactos que se exercen sobre as distintas poboacións do sistema intermareal e, en particular, sobre as interaccións que se establecen entre niveis tróficos.

A metodoloxía deseñada pode realizarse en calquera centro, mesmo naqueles sen equipamentos sequera básicos para realizar observación de mostras biolóxicas (é dicir, en ausencia de microscopios, estufas, balanzas, etc.). A observación non require de exhaustivos coñecementos taxonómicos e só se centra en organismos macroscópicos ben coñecidos. Este protocolo permite procesar as mostras nun espazo de tempo curto e axustado aos horarios de clase do centro.

Ao inicio da actividade o profesorado explicou ao alumnado, de xeito breve (non debe superar os 10 minutos), que é unha pradaría de fanerógamas mariñas, que especies a constitúen, que hábitat ocupan e cales son as adaptacións principais que desenvolveron estes organismos, inicialmente terrestres, para conseguir colonizar con éxito o medio mariño. A continuación, describíronse as características principais destes ecosistemas e os bens e servizos que fornecen á especie humana. Finalmente, presentouse ao alumnado o escenario de regresión ecolóxica que están a experimentar estes ecosistemas en todo o planeta e describíronse as presións ambientais máis relevantes ás que están sometidos, así como os impactos que estas presións ocasionan nestas comunidades. Tratáronse de xeito particular os impactos asociados á actividade marisqueira coa que estas especies de fanerógamas coexisten dende hai moitas décadas, coexistencia que, aínda que amosa dificultades no presente, debemos intentar manter no futuro.

Nunha segunda fase da actividade no campo, o profesorado traballou de xeito interactivo co alumnado na definición das hipóteses que deberán ser comprobadas. Neste caso, a primeira hipótese formulada foi que a presenza dunha pradaría da especie Zostera nolteii está asociada a unha maior diversidade da fauna. A segunda hipótese a comprobar foi que o tamaño das manchas nas que esta especie se distribúe no espazo está relacionado coa diversidade de macroinvertebrados, de xeito que as manchas de menor tamaño, que poderían resultar das perturbacións físicas ocasionadas 
polo marisqueo, estarán caracterizadas por unha menor diversidade fáunica. Unha vez definidas as hipóteses, o profesorado continuou fomentando o debate coa finalidade de que o alumnado aportara as súas contribucións na procura dun deseño de mostraxe axeitado para recoller os datos que permitirían responder as preguntas expostas e comprobar as hipóteses formuladas. Definíronse tres tamaños de mancha da poboación de Zostera nolteii: mancha principal (a de maior tamaño), mancha de tamaño intermedio e mancha de tamaño pequeno. Ao longo desta fase explicativa do traballo de campo, fíxose incidencia especial na aplicación do método científico, definindo con claridade todas as súas fases.

A primeira aproximación dos estudantes á pradaría consistiu na observación por parte destes da morfoloxía da planta, tanto na súa parte aérea (estrutura foliar), coma do seu rizoma. É de interese que o alumnado comprobe a dificultade que a presenza de rizomas ocasiona na acción de escavar o sedimento, relacionando esta experiencia co conflito que se establece entre a presenza da especie e a actividade extractiva de moluscos, o marisqueo.

Tras esta primeira fase explicativa e de definición do deseño de mostraxe, o alumnado, organizado en grupos de catro persoas, comezou a realizar a toma de mostras desprazándose ás áreas de mostraxe cuxas características foran previamente definidas: zonas colonizadas pola pradaría e zonas adxacentes de area sen colonizar. Dentro das zonas de pradaría, definíronse as 3 áreas de acordo ao seu tamaño, tal como foi descrito. A posición xeográfica de cada área foi rexistrada utilizando un GPS instalado nun teléfono móbil. Posteriormente, estimaron a dimensión da mancha de Zostera nolteii cunha cinta métrica. A continuación tomaron aleatoriamente unha mostra de sedimento e Zostera nolteii utilizando unha testemuña (tubo de PVC), de $15 \mathrm{~cm}$ de diámetro e $15 \mathrm{~cm}$ de profundidade, que introduciron $10 \mathrm{~cm}$ no sedimento. $\mathrm{O}$ sedimento, xunto coas plantas e a fauna asociada, introduciuse en bolsas de plástico marcadas previamente co código do punto de mostraxe. Rematada a toma de mostras, regresouse ao Centro, neste caso o IES Virxe do Mar de Noia. 


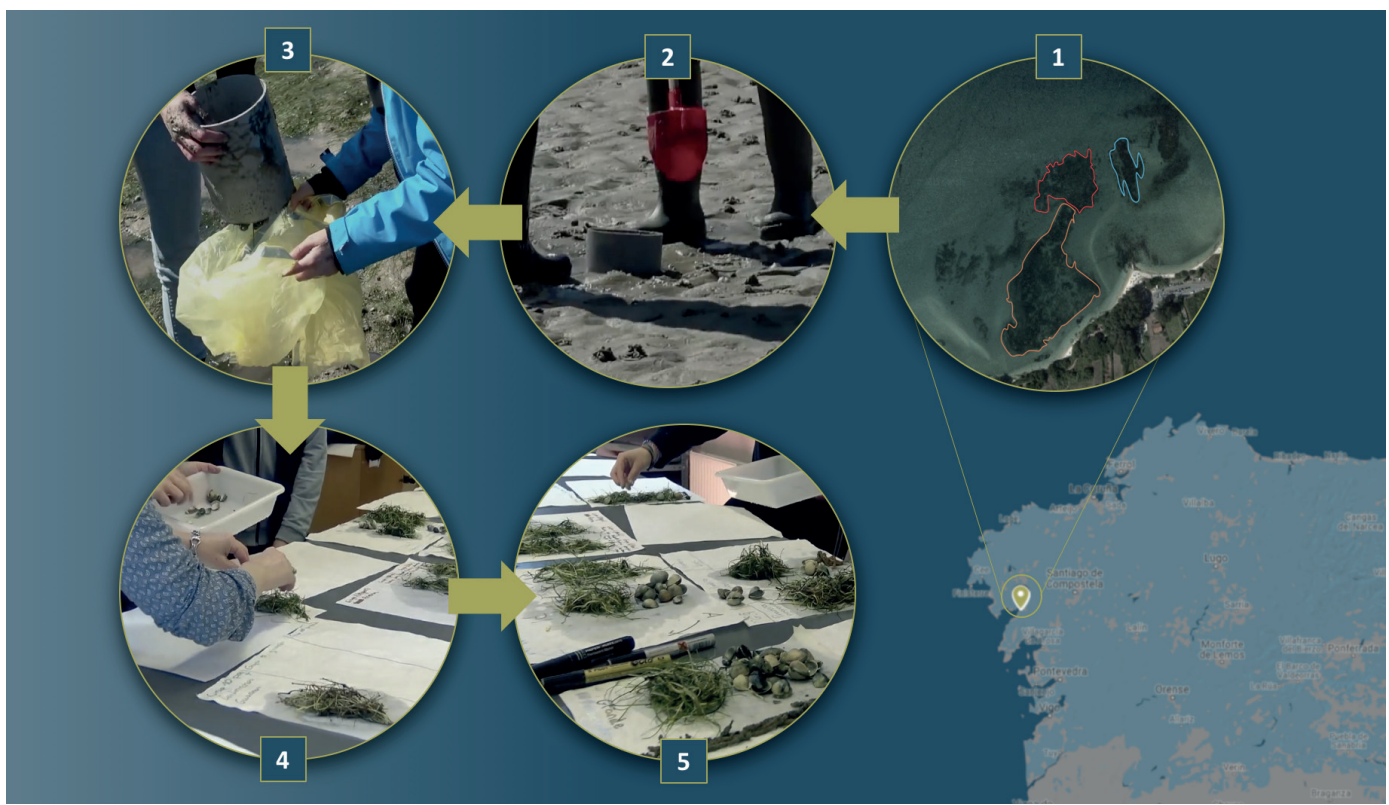

Figura 2. Metodoloxía da investigación científico escolar: (1) delimítanse as tres áreas da pradaría de acordo ao seu tamaño grande, medio e pequeno; (2) tomáronse mostras en diferentes posicións do sistema intermareal, a través de testemuñas, nas pradarías grandes e pequenas e na zona sen pradaría; (3) introdúcese o sedimento en bolsas de plástico; (4) retírase a fanerógama Zostera nolteii do sedimento e (5) clasifícanse os macroinvertebrados bentónicos atopados na mostra en grupos taxonómicos.

Unha vez no laboratorio da escola, cada un dos grupos procedeu ao procesado das mostras recollidas. En primeiro lugar, os estudantes transferiron cada mostra a unha bandexa de plástico, procedendo a retirar a fanerógama Zostera nolteii, separando follas e rizomas, que colocaban sobre una folla de papel de laboratorio. Na bandexa ficou o sedimento xunto coa fauna macroscópica. A continuación revisaron coidadosamente a totalidade da mostra recollendo todos os organismos animais que encontraran. Estes foron tamén colocados sobre unha folla de papel de laboratorio agrupados por grupos taxonómicos. A fase final do procesado de mostras consistiu no reconto do número de individuos dos grupos fáunicos, mentres que o material vexetal se deixou exposto ao aire durante unha semana para o seu secado, período tras o cal se cuantificou a biomasa de Zostera nolteii mediante pesada cunha balanza.

\section{RESULTADOS}

O resultado do procesado das mostras ilústrase na táboa 2, onde se amosan os grupos taxonómicos animais identificados en cada mostra e se visualiza a súa presenza en cada unha das tres zonas de mostraxe, o que permite, de xeito cualitativo, extraer conclusións preliminares referentes á confirmación, ou non, dalgunhas das hipóteses formuladas o día da realización da mostraxe. 
Táboa 1. Presencia (verde) ou ausencia (vermello) dos diferentes grupos taxonómicos animais atopados en cada punto de mostraxe ( $a, b, c, d, e, f, g, h, i)$ nas zonas sen Zostera, con manchas pequenas de Zostera e con manchas grandes de Zostera.

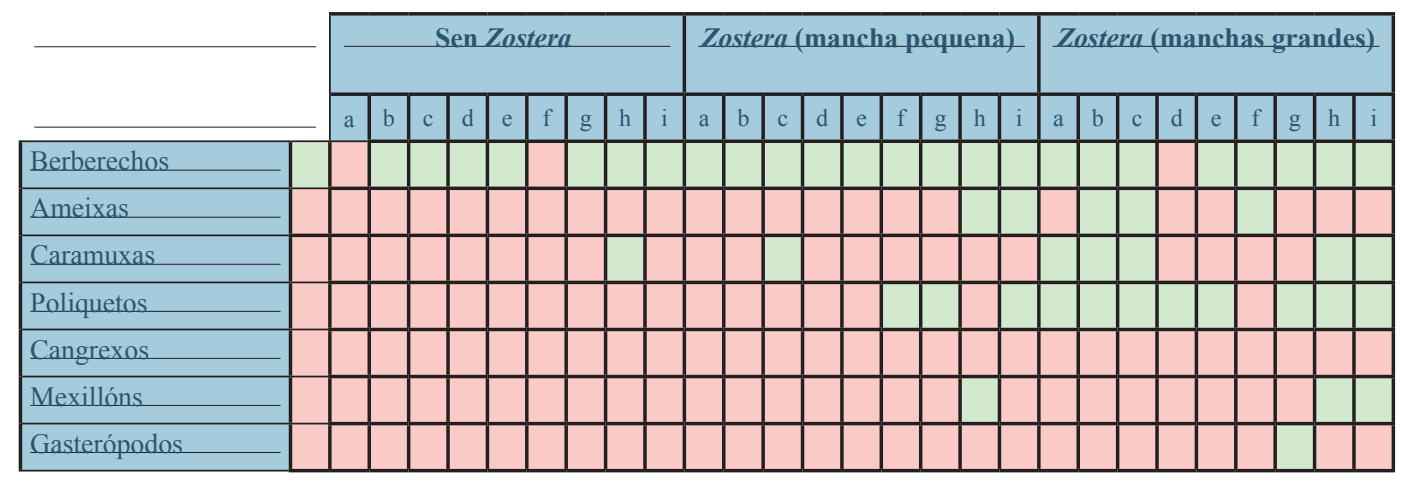

Os datos obtidos na actividade permitiron que os estudantes foran quen de extraer as seguintes conclusións:

1) A presenza de Zostera nolteii estaba asociada a unha maior diversidade animal no sistema intermareal de substrato brando.

2) As manchas da fanerógama de tamaño pequeno están caracterizadas por amosar unha menor diversidade fáunica que as de tamaño grande. De aquí conclúese que a fragmentación das pradarías de Zostera nolteii conduce a un descenso da diversidade do ecosistema, o que estaría potencialmente relacionado cunha redución dos servizos ecosistémicos que esta fornece.

O alumnado traballou con eficacia e axilidade, logrando nunha mañá facer a mostraxe das catro especies de bivalvos nos 500 metros no infralitoral medio e dos 500 metros no infralitoral inferior relativa á investigación sobre a abundancia dos bivalvos neste banco marisqueiro (Sóñora e Alonso-Méndez, 2018), pasando a continuación a facer a mostraxe de Zostera nolteii que se describe neste artigo, que ocupa unha superficie importante no infralitoral superior do mesmo areal. Unha vez rematada a mostraxe, a metade do grupo realizou o traballo de laboratorio, e a outra metade concentrouse no tratamento de datos utilizando un documento Excel colaborativo, do cal se derivaron representacións gráficas das abundancias observadas, restando tempo para argumentar a nivel metacognitivo cos científicos que dirixiron a investigación sobre a importancia deste tipo de procesado de datos e sobre a relación dos dous tipos de mostraxe realizados pola mañá.

No inicio do curso 2019-2020 todos os participantes na actividade de 2019 que se describe neste artigo inscribíronse no Club de Ciencias de Climántica co obxectivo de continuar co desenvolvemento da serie de datos e outras investigacións colaborativas coa Rede de Climántica próxima a Noia, quedando xa fixado unha mostraxe en marzo de 2020 a desenvolver entre os alumnos da materia Climántica de libre configuración e os alumnos do Instituto Español Giner de los Ríos. Está previsto que os resultados obtidos se presenten nunha exposición conxunta en galego e portugués o Día das Letras Galegas, en Lisboa. 


\section{CONCLUSIÓNS}

As principais conclusións deste artigo quedan organizadas en tres bloques. O primeiro deles recolle aquelas relacionadas coas hipóteses científicas formuladas, o segundo recolle aquelas relativas ás implicacións didácticas e o terceiro refírese ao interese da colaboración Ecoloxía Escola:

a) Conclusións relacionadas coas hipóteses científicas formuladas:

- Púxose en marcha a toma de mostras dunha serie complexa que integra as catro especies de bivalvos de interese comercial de Testal e a súa relación coa fanerógama Zostera nolteii que habita no mesmo infralitoral, establecendo así as bases de estudo que permitirán determinar as relacións existentes entre a diversidade de organismos animais no substrato brando e a presenza de Zostera nolteii neste banco marisqueiro, así como apoiar os estudos relativos á xestión racional do recurso nas respostas que vaian demandando os impactos do cambio global no recurso.

- Atopouse que existía relación entre o tamaño das manchas de Zostera nolteii e a diversidade de organismos animais.

b) Conclusións relativas ás implicacións didácticas

- A formación de estudantes en conexión directa con familias de mariscadores mellora a sensibilización social sobre a relevancia de realizar unha xestión dos ecosistemas utilizados polo ser humano, que estea baseada no coñecemento, a través do seu estudo e investigación.

- A actividade promove a sensibilización do alumnado sobre a importancia de facilitar a coexistencia da fanerógama mariña Zostera nolteii e os bivalvos de interese comercial do banco marisqueiro de Testal, para así preservar a integridade ecolóxica e, consecuentemente, os servizos que estes ecosistemas fornecen.

- Esta investigación científico - escolar facilita que o alumnado coñeza a diversidade de organismos que habitan enterrados no sistema intermareal de substrato brando, aplicando destrezas no procesado de mostras fangosas no laboratorio, facéndoos conscientes da existencia deste tipo plantas somerxidas e da súa relevancia ecolóxica e susceptibilidade diante dos impactos do cambio global.

c) Conclusións relativas ao interese da colaboración da Ecoloxía e da Escola:

- A Ecoloxía e a Escola poden colaborar de forma eficaz obtendo un beneficio mutuo: a ciencia da Ecoloxía amplía as posibilidades de obter datos relevantes en ecosistemas de alto interese na mitigación e na adaptación ao cambio global en xeral, e climático en particular, e a Escola recibe formación de elevada calidade e valor en competencias científicas tecnolóxicas.

- As respostas locais ao cambio global requiren cada vez máis series temporais cun número mínimo de entre 10 e 30 anos para establecer correlacións significativas entre variables ecolóxicas e datos ambientais ou presións antropoxénicas, como é o caso, por exemplo, 
da relación entre a evolución temporal do tamaño das manchas de Zostera nolteii e a diversidade de animais mariños, con especial énfase nas especies de bivalvos de interese comercial.

- Resulta de imperiosa necesidade a formación da cidadanía en xeral para responder ao cambio global, e neste sentido, este tipo de modelo didáctico establece unha triangulación eficaz escola - ciencia - cidadanía que forme, informe, sensibilice e comprometa a todas as xeracións no reto dende o interese que esperta a formación escolar infanto-xuvenil entre as diferentes xeracións familiares.

- A investigación das respostas dos ecosistemas ao cambio global require estudos científicos de tal intensidade e continuidade no tempo que fai necesario o establecemento de culturas de ciencia cidadá. Neste tipo de alianzas escola-ciencia-asociación de produtores xéranse nos máis novos sinerxías, culturas, hábitos e técnicas que facilitarán a súa incorporación a iniciativas de ciencia cidadá similares ao longo da súa formación permanente e, posteriormente, ao longo da súa vida adulta.

\section{REFERENCIAS}

Álvarez, A. e del Río, P. (1990). Educación y desarrollo: La teoría de Vygotsky y la Zona de desarrollo próximo. En C. Coll, J. Palacios e A. Marchesi (Comps.), Desarrollo psicológico y educación, II (pp. 93-119). Psicología de la Educación. Madrid: Alianza.

Ausubel, D. P. (2000). Adquisición y retención del conocimiento. Una perspectiva cognitiva. Barcelona: Paidós.

Bruner, J. S. (1985). Realidad mental y mundos posibles. Los actos de la imaginación que dan sentido a la experiencia. Barcelona: Gedisa. (Versión en español 1996).

Barañano, C., Fernández, E., Méndez, G. e Troncoso, J. (2017). Resilience of Zostera marina L. habitats and response of the macroinvertebrate community to physical disturbance caused by clam harvesting. Marine Biology Research, 13(9), 955-966. DOI: https://doi.org/10.1080/17 451000.2017.1307989

Barañano, C., Fernández, E. e Méndez, G. (2018). Clam harvesting decreases the sedimentary carbon stock of a Zostera marina meadow. Aquatic Botany, (146), 48-57. DOI: https://doi. org/10.1016/j.aquabot.2017.12.002

Boese, B. L. (2002). Effects of recreational clam harvesting on eelgrass (Zostera marina) and associated infaunal invertebrates; in situ manipulative experiments. Aquatic Botany, (73), 63-74. DOI: https://doi.org/10.1016/S0304-3770(02)00004-9

Constanza, R. et al. (1997). The value of the world's ecosystem services and natural capital. Nature, (387), 253-260. DOI: https://doi.org/10.1038/387253a0

Dewey, J. (1972). A pedagogical experiment. En J. Dewey, Early works of John Dewey. Vol. 5 (pp. 244-246). Carbonale: Southern Illinois University Press.

Duarte, C. M. e Chiscano, C. L. (1999). Seagrass biomass and production: A reassessment. Aquatic Botany 65: 159-174. https://doi.org/10.1016/S0304-3770(99)00038-8 
Fernandes, M., Bryars, S., Mount, G. e Miller, D. (2008). Seagrasess as a sink for wastewater nitrogen: The case of the Adelaide metropolitan coast. Mar. Poll. Bull., (58), 303-308. DOI: https://doi.org/10.1016/j.marpolbul.2008.10.006

Follett, E., Hays, C. G. e Nepf, H. (2019). Canopy-mediated hydrodynamics contributes to greater allelic richness in seeds produced higher in meadows of the coastal eelgrass Zostera marina. Frontiers in Marine Science, (6), 1-13. DOI: https://doi.org/10.3389/fmars.2019.00008

Fonseca, M. S., Kenworthy, W. J. e Whitfield. P. E. (2000). Temporal dynamics of seagrass landscapes: A preliminary comparison of chronic and extreme disturbance events. Biología Marina Mediterránea, (7), 373-376.

Fourqurean, J. W. et al. (2012). Seagrass ecosystems as a globally significant carbon stock. Nat. Geosci., 5(7), 505-509. DOI: https://doi.org/10.1038/ngeo1477

García-Redondo, V., Bárbara, I. e Díaz-Tapia, P. (2019). Zostera marina meadows in the northwestern Spain: distribution, characteristics and anthropogenic pressures. Biodiversity and conservation, 28(7), 1743-1757. DOI: https://doi.org/10.1007/s10531-019-01753-4

Green, E. P. e Short, F. T. (Eds.) (2003). World Atlas of Seagrasses. Berkeley. University of California Press.

de Groot, R. et al. (2012). Global estimates of the value of ecosystems and their services in monetary units. Ecosystem Services, 1(1), 50-61. DOI: https://doi.org/10.1016/j.ecoser.2012.07.005

Hemminga, M. e Duarte, C. M. (2000). Seagrass Ecology. Cambridge University Press. DOI: https:// doi.org/10.1017/CBO9780511525551

Heck, K. L., Hays, C. e Orth, R. J. (2003). A critical evaluation of the nursery role hypothesis for seagrass meadows. Mar. Ecol. Prog. Ser, (253), 123-136. DOI: https://doi.org/10.3354/ meps 253123

Kilpatrick, W. (1921). The Project method: The use of the purposeful act in the educative process. New York: Teachers College Press.

Lamb, J. B. et al. (2017). Seagrass ecoystems reduce exposure to bacterial pathogens of humans, fishes and invertebrates. Science, (355), 731-733. DOI: https://doi.org/10.1126/science. $\underline{\text { aal1956 }}$

Morin, E. (1990). Introducción al pensamiento complejo. Barcelona: Gedisa.

Norlund, L. M., Koch, E. W., Barbier, E. B. e Creed, J. C. (2016). Seagrass ecosystem services and their variability across genera and geographical regions. PLoS ONE, 11(10): e0163091. DOI: https://doi.org/10.1371/journal.pone.0163091

Norlund, L. M., Unsworth, R. K. F., Gullstrom, M. e Cullen-Unsworth, L. C. (2017). Global significance of seagrass fishery activity. Fish and Fisheries, (19), 399-412. DOI: https://doi. org/10.1111/faf.12259

Olsen, J. L. et al. (2016). The genome of the seagrass Zostera marina reveals angiosperm adaptation to the sea. Nature, (530), 331-335. DOI: https://doi.org/10.1038/nature16548

Orth, R. J. et al. (2006). A global crisis for seagrass ecosystems. Bioscience, (56), 987-996. DOI: https://doi.org/10.1641/0006-3568(2006)56[987:AGCFSE]2.0.CO;2

Pardo Pérez, J. C. (2015). Construtivismo, construtivismos e o lugar que ocupan o suxeito e o contexto social na construción do coñecemento: unha mirada desde a posmodernidade. Conferencia pronunciada na I Xornada de Debate Aíovai Educación. Bertamiráns, 16 de maio. 
Recuperado de http://www.edu.aiovai.org/construtivismo-construtivismos-e-o-lugar-queocupan-o-suxeito-e-o-contexto-social-na-construcion-do-conecemento-unha-mirada-desdea-posmodernidade

Ruiz, G. M. et al. (2000). Invasion of coastal marine communities in North America: Apparent patterns, processes, and biases. Annual Review of Ecology and Systematics, (31), 481-531. DOI: https://doi.org/10.1146/annurev.ecolsys.31.1.481

Ruiz, J. M., Guillén, J. E., Ramos Segura, A. e Otero, M. M. (Eds.) (2015). Atlas de las praderas marinas de España. . Murcia-Alicante-Málaga: IEO/IEL/UICN.

Sóñora, F. (2007). Proyecto Climántica. Revista Magisterio Internacional, (29), 74-75.

Sóñora, F. (2011). Innovación para la sociedad del cambio climático. Aula de Innovación Educativa, (206), 51-56.

Sóñora, F. e Alonso-Méndez, A. (2018). Ocean Under Global Change: From Science to School. International Journal of Environmental and Science Education, 13(2), 97-112.

Troncoso, J. (2017). Resilience of Zostera marina L. habitats and response of the macroinvertebrate community to physical disturbance caused by clam harvesting. Marine Biology Research, 13(9), 955-966. DOI: https://doi.org/10.1080/17451000.2017.1307989

Unsworth, R. K. F., Williams, B., Jones, B. L. e Cullen-Unsworth, L. C. (2017). Rocking the boat: damage to eelgrass by swinging boat moorings. Frontiers in Plant Science, (8). DOI: https:// doi.org/10.3389/fpls.2017.01309

Vygotski, L. (1978a). Pensamiento y Lenguaje. Buenos Aires: La Pléyade.

Vygotski, L. (1978b). La mente en la sociedad: el desarrollo de las funciones psicológicas superiores. Harvard University Press: Cambridge.

Walker, D. I., Kendrick, G. A. e McComb, A. J. (2006). Decline and recovery of seagrass ecosystems: the dynamics of change. En: A. W. D. Larkum, R. J.Orth e C. M. Duarte, (Eds.), Seagrasess: Biology, Ecology and Conservation. Dordrecht (The Netherlands). Springer.

Waycott, M. et al. (2009). Accelerating loss of seagrasses across the globe threatens coastal ecosystems. Proc. Nat. Acad. Sci., 106(30), 12377-12381. DOI: https://doi.org/10.1073/ pnas.0905620106

\section{Nota sobre 0 artigo.}

Este artigo pertence ao Proxecto Climántica (www.climantica.org), recomendado dende 0 ano 2010 para o seu uso docente polo Alto Comisionado das Nacións Unidas para o Cambio Climático.
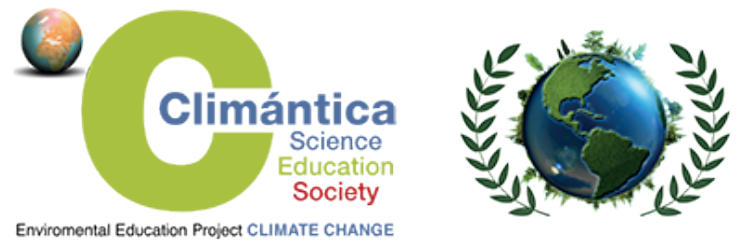